\title{
Modulation of Neurological Deficits and Expression of Glutamate Receptors during Experimental Autoimmune Encephalomyelitis after Treatment with Selected Antagonists of Glutamate Receptors
}

\author{
Grzegorz Sulkowski, Beata Dąbrowska-Bouta, and Lidia Strużyńska \\ Laboratory of Pathoneurochemistry, Department of Neurochemistry, Mossakowski Medical Research Centre, \\ Polish Academy of Sciences, 5 Pawińskiego Street, 01-106 Warsaw, Poland \\ Correspondence should be addressed to Grzegorz Sulkowski; gsulkowski@imdik.pan.pl
}

Received 5 April 2013; Accepted 2 June 2013

Academic Editor: George Perry

Copyright (c) 2013 Grzegorz Sulkowski et al. This is an open access article distributed under the Creative Commons Attribution License, which permits unrestricted use, distribution, and reproduction in any medium, provided the original work is properly cited.

\begin{abstract}
The aim of our investigation was to characterize the role of group I mGluRs and NMDA receptors in pathomechanisms of experimental autoimmune encephalomyelitis (EAE), the rodent model of MS. We tested the effects of LY 367385 (S-2-methyl4-carboxyphenylglycine, a competitive antagonist of mGluR1), MPEP (2-methyl-6-(phenylethynyl)-pyridine, an antagonist of mGluR5), and the uncompetitive NMDA receptor antagonists amantadine and memantine on modulation of neurological deficits observed in rats with EAE. The neurological symptoms of EAE started at 10-11 days post-injection (d.p.i.) and peaked after 12-13 d.p.i. The protein levels of mGluRs and NMDA did not increase in early phases of EAE (4 d.p.i.), but starting from 8 d.p.i. to 25 d.p.i., we observed a significant elevation of mGluR1 and mGluR5 protein expression by about $20 \%$ and NMDA protein expression by about $10 \%$ over the control at 25 d.p.i. The changes in protein levels were accompanied by changes in mRNA expression of group I mGluRs and NMDARs. During the late disease phase (20-25 d.p.i.), the mRNA expression levels reached $300 \%$ of control values. In contrast, treatment with individual receptor antagonists resulted in a reduction of mRNA levels relative to untreated animals.
\end{abstract}

\section{Introduction}

Experimental autoimmune encephalomyelitis (EAE) is an animal model used in investigations of the pathomechanisms of multiple sclerosis (MS). MS is an inflammatory demyelinating disease of the central nervous system (CNS) that often affects young adults. The disease is characterized by damage and loss of the oligodendrocytes that myelinate axons and facilitate neurotransmission. The etiology of MS has not been established.

Recent studies have suggested that glutamate neurotoxicity may be involved in the pathogenesis of MS $[1,2]$. Disturbances in glutamate levels in cerebrospinal fluid and changes in expression of ionotropic and metabotropic glutamate receptors have been observed in the brains of MS patients [3].

Glutamate is the main excitatory neurotransmitter in mammalian brain and plays an important role in both physiological and pathological mechanisms operating in the CNS. The extracellular level of glutamate must be tightly controlled because an excess of this neurotransmitter leads to overstimulation of glutamate receptors and subsequent cell death. This phenomenon is known as excitotoxicity $[2,4]$. There is evidence that overactivation of glutamate receptors contributes to the process of cell death in numerous chronic neurodegenerative disorders such as motor neuron disease (MND), amyotrophic lateral sclerosis (ALS), Huntington's disease, Parkinson's disease, and Alzheimer's disease [4-9]. Oligodendrocytes, the myelin-producing cells of the CNS, are highly vulnerable to glutamate excitotoxicity. It was suggested that glutamate released by macrophages might be involved in axonal damage and oligodendrocyte pathology in MS lesions [10]. The observation that excitotoxicity is one of the pathomechanisms operating during the course of neurodegenerative diseases such as MS suggests 
that anti-glutamatergic agents may exert neuroprotective action.

While ionotropic NMDA-, AMPA-, and kainate-type glutamate receptors (iGluRs) mediate fast synaptic transmission, metabotropic glutamate receptors (mGluRs) (mGluR1 and mGluR5) modulate neuronal excitability and development, synaptic plasticity, transmitter release, and memory function via a variety of intracellular second messenger systems [1113]. Functional interactions between ionotropic and group I metabotropic glutamate receptors have been identified. Electrophysiological experiments have shown functional interplay between mGlul/5 and NMDA receptors in various structures of the brain where activation of mGlu5 receptors enhances NMDA-evoked responses [14].

Previous studies have indicated a role of NMDA receptors in the pathogenesis of EAE and in the loss of blood-brain barrier (BBB) integrity which is involved in the pathomechanisms of the disease [15]. It has been found that memantine, an antagonist of NMDARs, modifies the neurological course of EAE and prevents the breakdown of the $\mathrm{BBB}[15,16]$. In addition to NMDA receptors, group I mGluRs may participate in glutamate-mediated neurotoxicity which has been demonstrated in cultured cerebellar granule neurons [17]. Administration of the mGluR1 antagonist LY 367386 was found to induce dose-dependent partial neuroprotection. When LY 367386 was administered with MK-801, an uncompetitive NMDA receptor antagonist, complete prevention of glutamate-induced cell death was observed. Differences in the neuroprotective effects of antagonists of group I mGluRs between two ischemia models (adult gerbil model of transient forebrain ischemia versus rat model of perinatal asphyxia) were also observed [18].

We thus decided to characterize the role of mGluR G I receptors and NMDA receptors in pathogenesis of EAE and investigate the possibility of using antagonists of these receptors to modulate their expression in Lewis rats with EAE. We tested the effect of the glutamate receptor antagonists amantadine and memantine (uncompetitive NMDA receptor antagonists) as well as antagonists of mGluR G I : LY 367385 (a competitive antagonist of mGluR1), and MPEP (a noncompetitive antagonist of mGluR5) on the development of neurological symptoms during EAE. The drugs were administered individually or, with the assumption that the neuroprotective effect would be enhanced, the NMDAR antagonists were administered in combination with antagonists of group I mGluRs. We also investigated the effect of the antagonists on mRNA and protein levels of mGluR1, mGluR5 and NMDA receptors.

\section{Materials and Methods}

2.1. Animal Model. Procedures for all animal experiments were approved by the local Ethics Committee. Experiments were performed on female Lewis rats weighing between about $180-200 \mathrm{~g}$. The rats were arranged into 7 groups $(1 \mathrm{control}$ group and 6 experimental groups which were subjected to different recovery periods following drug treatments). To induce experimental autoimmune encephalomyelitis (EAE), we immunized the rats subcutaneously in both hind feet with an inoculum containing guinea pig spinal cord homogenate emulsified in Freund's complete adjuvant containing $5.5 \mathrm{mg} / \mathrm{mL}$ Mycobacterium tuberculosis H37Ra (Difco, Detroit, MI, USA).

Rats were housed under environmentally controlled conditions and were permitted free access to food and water. Body weights and neurological deficits were determined daily according to the following scale: 0 , no signs; 1 , flaccid tail; 2, impairment of fighting reflex and/or loss muscle tone in hind limbs; 3, complete paralysis of hind limbs; 4, paraplegia; and 5, moribund state/death [19-21]. Sham-immunized rats (control group) received subcutaneous injections of Freund's complete adjuvant containing M. tuberculosis only (Difco, Detroit, MI, USA).

Amantadine was administered at a dose of $100 \mathrm{mg} /$ $\mathrm{kg}$ b.w./day. Memantine was administered at a dose of $60 \mathrm{mg} /$ kgb.w./day. LY 367385 and MPEP were administered at doses of $10 \mathrm{mg} / \mathrm{kg}$ b.w./day. The drugs were dissolved in PBS and administered intraperitoneally to the EAE rats either separately or in combination daily for 7 consecutive days, starting from 5 d.p.i. to 11 d.p.i.

2.2. Materials. During the experiments, the rats were monitored until days $4,8,12,20$, or 25 after the initial injection inducing EAE or after drug administration between 5-11 d.p.i. At the respective time points, four rats of each group were killed to obtain tissue for immunoblotting and realtime PCR analyses together with respective controls. The brains were rapidly removed and tissues were then frozen in liquid nitrogen and stored at $-70^{\circ} \mathrm{C}$ for further experiments. To obtain homogenates for immunoblots, the forebrains were homogenized in $50 \mathrm{mM}$ phosphate buffer ( $\mathrm{pH} 7.4$ ) containing $10 \mathrm{mM}$ EGTA, $10 \mathrm{mM}$ EDTA, $0.1 \mathrm{mM}$ PMSF, and $100 \mathrm{mM} \mathrm{NaCl}$ in the presence of protease inhibitor cocktail $(1 \mu \mathrm{g} / \mathrm{mL}$ leupeptin, $0.1 \mu \mathrm{g} / \mathrm{mL}$ pepstatin, and $1 \mu \mathrm{g} / \mathrm{mL}$ aprotinin).

2.3. Western Blot Analysis. Brain homogenates were subjected to SDS-polyacrylamide gel electrophoresis and examined to determine protein expression levels of NMDARs and mGluRs G I (group I of metabotropic glutamate receptors); mGluR1 and mGluR5. The protein concentration in brain homogenates was determined using the method of Lowry et al. [22]. Proteins ( $20 \mathrm{~g}$ ) were separated on $10 \%$ polyacrylamide gel and transferred to nitrocellulose membrane according to the Laemmli procedure [23]. Blots were blocked in PBS buffer containing $0.1 \%$ Tween-20 and 5\% non-fat milk (TPBS) for $1.5 \mathrm{~h}$. After washing $(3 \times 10 \mathrm{~min})$ in TPBS buffer, the blots were incubated overnight with primary monoclonal antibodies against NMDAR $(1: 500)$ or mGluRs $(1: 1000)$ and subsequently, after washing with TPBS $(3 \times$ $10 \mathrm{~min})$, with secondary antibodies conjugated with HRP (1:6000). A monoclonal antibody against $\beta$-actin $(1: 500)$ was used as an internal standard. Bands were detected with the chemiluminescence ECL kit (Amersham), exposed 1020 min to Hyperfilm ECL (Amersham), and densitometric analysis of band patterns was performed using UltraScan XL (Pharmacia). 
TABLE 1: Characterization of the EAE animal model and clinical parameters in rats with EAE and after treatment with antagonists of glutamate receptors.

\begin{tabular}{|c|c|c|c|c|c|}
\hline & EAE & Amantadine & Memantine & LY 367385 & MPEP \\
\hline Animals with clinical sings (\%) & 96.2 & 100 & 100 & 100 & 100 \\
\hline Animals with severe EAE (\%) & 73.9 & $62.7^{*}$ & $63.6^{*}$ & 73.6 & 70.0 \\
\hline Lethality (\%) & 8.8 & 0 & 8.3 & 0 & 0 \\
\hline Inductive phase (days) & $10.6 \pm 2.4$ & $12.1 \pm 1.3^{*}$ & $12.2 \pm 2.1^{*}$ & $10.8 \pm 1.4$ & $10.5 \pm 1.5$ \\
\hline Maximal CI (score) & $4.5 \pm 0.3$ & $2.4 \pm 0.4^{*}$ & $2.6 \pm 0.6^{*}$ & $4.1 \pm 0.6$ & $3.9 \pm 0.5$ \\
\hline Cumulative CI (score) & $28.6 \pm 4.7$ & $19.6 \pm 1.6^{*}$ & $20.1 \pm 2.4^{*}$ & $26.98 \pm 0.5$ & $27.6 \pm 0.7$ \\
\hline Duration of disease (days) & $21.4 \pm 1.8$ & $18.6 \pm 1.6^{*}$ & $17.8 \pm 2.1^{*}$ & $20.98 \pm 1.9$ & $20.2 \pm 1.2$ \\
\hline Number of animals & 160 & 24 & 24 & 24 & 24 \\
\hline
\end{tabular}

The values represent the means $\pm \mathrm{SD} .{ }^{*} P<0.05$, significantly different when compared with rats with EAE.

2.4. Determination of the mRNA Levels of GluRs by Real-Time $P C R$. Total RNA was extracted from brain cortex using TRI Reagent (Sigma, St. Louis, MO, USA), and $2 \mathrm{~g}$ of RNA was reverse-transcribed using random primers and AMV reverse transcriptase (Applied Biosystems, Forest City, CA, USA). The RT-PCR conditions were reverse transcription at $42^{\circ} \mathrm{C}$ for $45 \mathrm{~min}$ and denaturation at $94^{\circ} \mathrm{C}$ for $30 \mathrm{~s}$. For quantitative real-time PCR analysis, TaqMan technology was applied. The rat glutamate receptor-specific primers used are as follows: for mGluR 1-ID: Rn00566625_ml*, gene symbol Grml; for mGluR 5-ID: Rn00566628_m1*, gene symbol Grm5; and for NMDARs ID: Rn01530724_ml*, gene symbol Narg2. The probe was obtained from Applied Biosystems (Forest City, CA, USA). In order to normalize the mRNA expression of glutamate receptors, actin levels were determined using the predeveloped TaqMan assay reagents (Applied Biosystems, Forest City, CA, USA). Real-time PCR was conducted on an ABI Prism 7500 system, using $5 \mu \mathrm{L}$ of RT product, TaqMan PCR Master Mix, primers and TaqMan probe in a total volume of $20 \mu \mathrm{L}$. The PCR cycle conditions were as follows: initial denaturation at $95^{\circ} \mathrm{C}$ for $10 \mathrm{~min}, 50$ cycles of $95^{\circ} \mathrm{C}$ for $15 \mathrm{~s}$, and $60^{\circ} \mathrm{C}$ for $1 \mathrm{~min}$. Each sample was analyzed in triplicate. The relative expression levels of the glutamate receptors were calculated using the standard curve method and normalized to actin.

2.5. Statistical Analysis. The results are expressed as percentages of control, and data are the mean SD from 3-4 experiments. Significance was assessed by one-way ANOVA. Dunnett's multiple comparison test was used to identify the changes that were significantly different from control values $\left({ }^{*} P<0.05,{ }^{* *} P<0.01,{ }^{* * *} P<0.001\right.$ versus control-healthy rats) or untreated rats with EAE at corresponding d.p.i. $\left({ }^{\#} P<\right.$ $0.05,{ }^{\# \#} P<0.01,{ }^{\# \# \#} P<0.001$ versus EAE animals after therapy with antagonists).

\section{Results}

3.1. The Influence of Drug Administration on the Course of the Disease. The neurological deficits observed during the course of EAE were classified daily according to the scale from $1+$ to $5+$ as described in Section 2. Neurological symptoms of EAE include progressive developmental paralysis

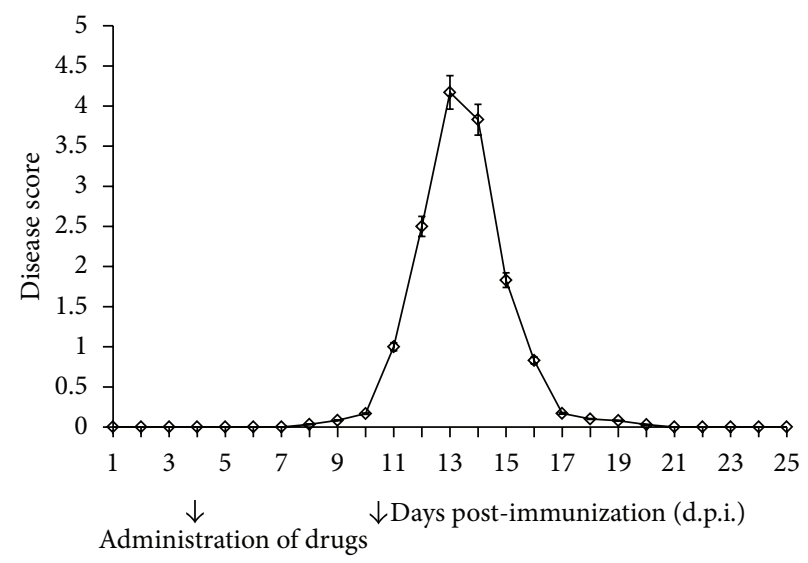

FIGURE 1: Scores of the neurological symptoms of animals during the course of EAE. The results are means \pm SD from more than 120 animals. The arrows in the diagram indicate the time point of drug administration in treated groups.

of tail and hind limbs and reduction of physical activity in experimental rats. The neurological symptoms of EAE started at 10-11 d.p.i. and peaked at 12-13 d.p.i. On 14 d.p.i. rats had attained partial recovery from neurological symptoms and full recovery was observed at 17 d.p.i. We did not observe any further neurological symptoms of the disease through to the end of the experiments at 25 d.p.i. (Figure 1).

We also noted changes in body weight during the course of EAE. In all experimental groups, the rats reached their highest body weight at approximately 8 d.p.i. At this time, body weights were in the same range in the EAE and drugtreated groups. Starting from 8 d.p.i. to 14 d.p.i, rats in all groups underwent a progressive $20-30 \%$ weight loss (data not shown). Detailed observations of EAE animals and clinical parameters during the experiment are presented in Table 1.

The effects of administration of glutamate receptor antagonists (amantadine, memantine, LY 367385, and MPEP) on neurological deficits during the course of EAE are illustrated in Figures 2(a) and 2(b) and presented in Table 1. We observed a statistically significant reduction of neurological symptoms in rats after administration of amantadine or memantine. In these experimental groups, the maximal neurological score was 2+ (flaccid tail, impairment of fighting reflex and/or 


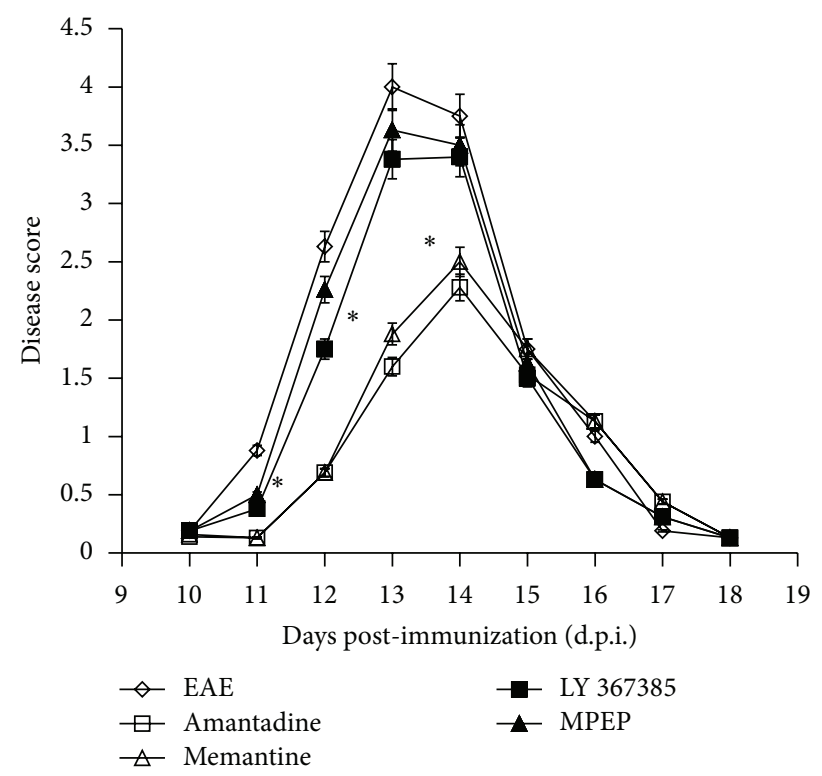

(a)

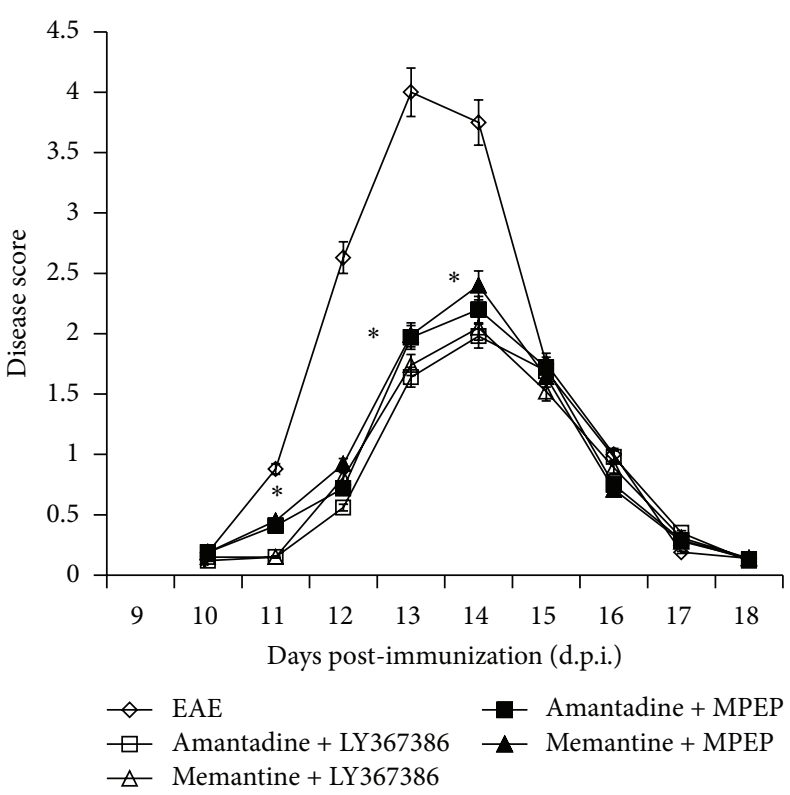

(b)

FIGURE 2: Scores of the neurological symptoms during the acute phase of EAE and after treatment with antagonists of glutamate receptors. Antagonist doses were as follows: amantadine $100 \mathrm{mg} / \mathrm{kg}$ b.w./day, memantine $60 \mathrm{mg} / \mathrm{kg}$ b.w./day, LY $36738510 \mathrm{mg} / \mathrm{kg}$ b.w./day, and MPEP $10 \mathrm{mg} / \mathrm{kg}$ b.w./day. These doses were administered separately (a) or in combination (b) from 5 to $11 \mathrm{~d} . p . i$. Neurological signs were recorded until recovery of the control EAE group at 25 d.p.i. The values indicate neurological score \pm SD. Results are combined data from four to eight animals in each group. ${ }^{*} P<0.05 ;{ }^{* *} P<0.01$ compared with untreated EAE rats.

loss muscle tone in hind limbs) and all experimental rats were in better neurological condition than the untreated rats with EAE. Administration of amantadine or memantine both had the effect of reducing the severity and duration of neurological deficits; the average cumulative index, duration of illness, and maximal score were reduced by factors of 8.5, 2.8, and 1.9, respectively, relative to the untreated EAE rats (Table 1). Further, the inductive phase of the disease was extended by a factor of 2.1 with administration of amantadine and memantine. We did not observe neuroprotective effects of mGluR G I antagonists. Administration of LY 367385 or MPEP did not influence neurological deficits and the condition of the experimental rats during the course of the disease while given separately (Figure 2(a), Table 1) or in combination with the NMDAR antagonists (amantadine and memantine). The neurological deficits and condition of examined animals were the same as in the case of treatment with amantadine or memantine exclusively (Figure 2(b)).

\subsection{Changes in the Expression Levels of Glutamate Receptors} after Drug Administration. To investigate the changes in protein and mRNA expression of both group I mGluRs and NMDA receptors during the course of EAE and after therapy with glutamate receptor antagonists, we performed Western blots and real-time PCR analysis. Western blots were used to evaluate the changes in the immunocontent of receptor protein in brain homogenates obtained from control rats, rats with EAE, and drug-treated rats. A strongly positive immunoreaction was observed in a single band near $206 \mathrm{kDa}$ for $\mathrm{mGluRs} \mathrm{G}$ I and $180 \mathrm{kDa}$ for NMDA receptors.
Our studies revealed changes in the level of mGluR 1 mRNA in immunized rats. Starting from 8 d.p.i. we observed a statistically significant increase in mGluR 1 mRNA, reaching $300 \%$ of the control value at 25 d.p.i. (Figure 3(a)). Changes in the mRNA level corresponded to the increase in protein expression observed from 12 to 25 d.p.i. These changes were only about $25 \%$ higher relative to the control level (Figure 3(b)). After administration of amantadine (Figure 3(c)) or memantine (Figure 3(d)), the animals developing EAE were found to have lower mGluR1 mRNA levels (by about $20 \%$ compared with control and almost $300 \%$ relative to untreated EAE rats at an appropriate time point after immunization). The expression of mGluR1 receptor protein remained at an elevated level 20\%-30\% above control values at 20-25 d.p.i. (Figures 3(d) and 3(f)). Administration of LY 367385 (mGluR1 antagonist) resulted in increased expression of mGluR1 mRNA by about $300 \%$ relative to control values (Figure 3(g)). These changes were accompanied by increased expression of the protein reaching $15-20 \%$ of control values (Figure 3(h)).

Trends in the level of expression of mGluR5 were found to be similar to the changes in mGluR1 expression. Levels of mGluR5 mRNA increased between 12-25 d.p.i. (Figure 4(a)) by about $80 \%$ compared to controls. Elevated expression of mGluR5 protein (approximately $20 \%$ ) in the same time range (12-25 d.p.i.) was also observed (Figure 4(b)). Administration of amantadine or memantine had the effect of decreasing the level of mGluR5 mRNA expression by about $20 \%$ compared to controls (normal rats) and by almost $100 \%$ compared to untreated rats with EAE at an appropriate time point after 


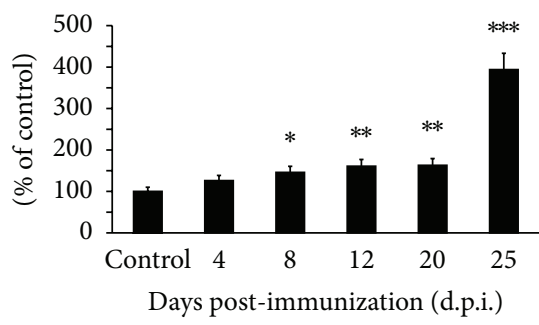

(a)

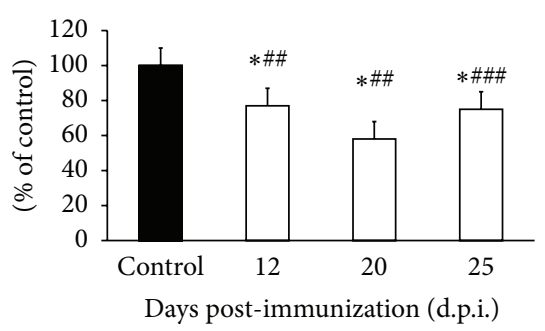

(c)

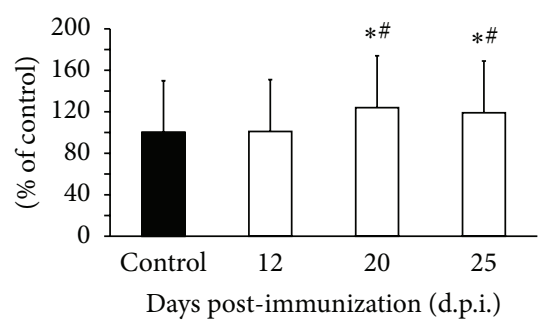

(e)

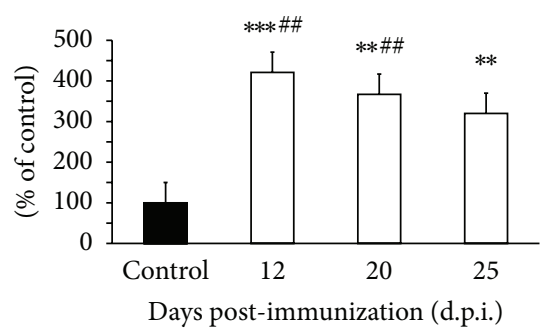

(g)

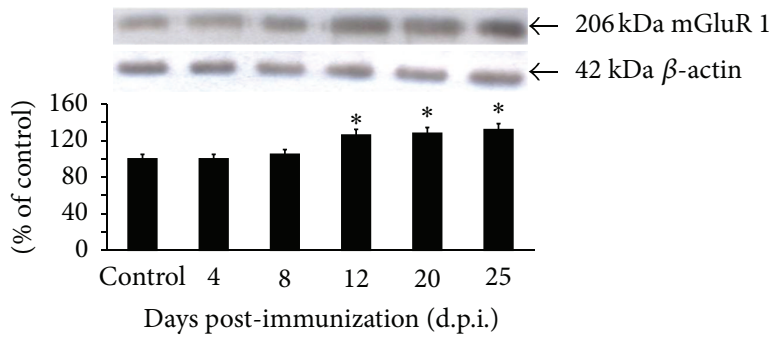

(b)

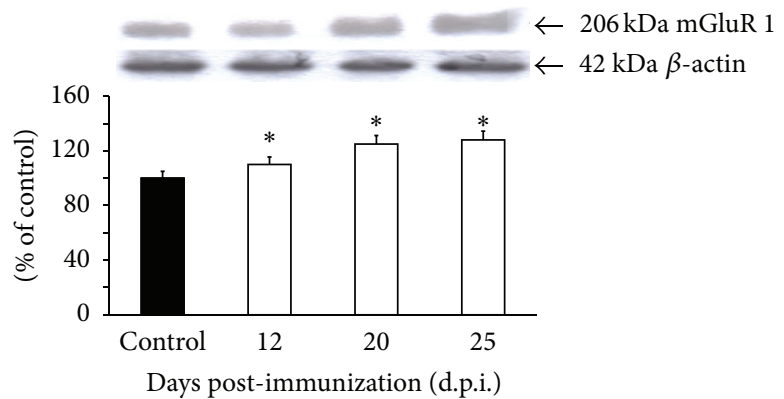

(d)

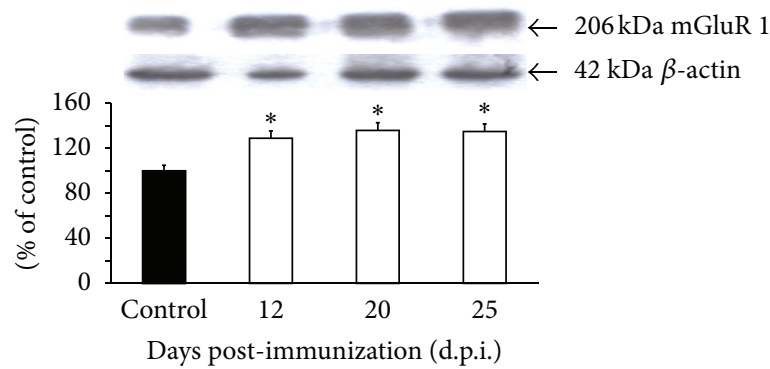

(f)

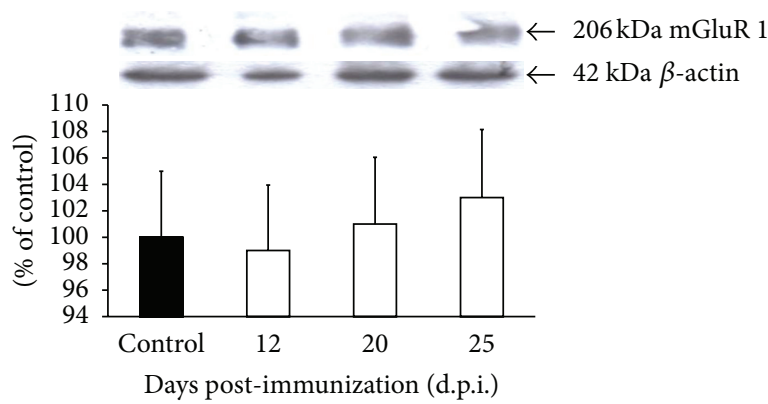

(h)

Figure 3: Expression of mGluR1 mRNA (a, c, e, and g) and protein (b, d, f, and h) in forebrain of control and EAE rats at different times post-immunization ( $\mathrm{a}$ and $\mathrm{b}$ ) and after therapeutic treatment with antagonists of glutamate receptors: amantadine (c and d), memantine (e and f), and LY 367385 (g and h). Total RNA was prepared from healthy control rats, rats with EAE, and rats with EAE after therapy at the indicated d.p.i. The mGluR1 mRNA levels were determined by quantitative real-time PCR (see Section 2) and normalized against actin. Graphs (a), (c), (e), and (g) present the results expressed as percentage of control from four independent experiments. ${ }^{*} P<0.05 ;{ }^{* *} P<0.01$; ${ }^{* * *} P<0.001$ different versus control (healthy untreated rats). ${ }^{\#} P<0.05 ;{ }^{\# \#} P<0.01$; ${ }^{\# \#} P<0.001$ different versus EAE rats not subjected to therapy in corresponding d.p.i. (one-way ANOVA followed by Dunnett's multiple comparison posttest). Representative immunoblots show the expression of mGluR 1 receptor protein in forebrain homogenates of (b) control rats and rats with EAE at different times postimmunization, (d) amantadine-treated EAE rats, (f) memantine-treated rats with EAE, and (h) LY 367385-treated rats with EAE. The results are expressed as percentage of control. Graphs (b), (d), (f), and (h) present the results of densitometric analysis, normalized to $\beta$-actin, of four independent immunoblots, each done from distinct brain; ${ }^{*} P<0.05$ (one-way ANOVA with post hoc Dunnett's test). 


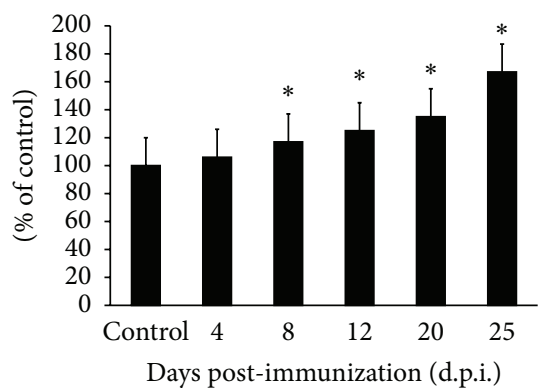

(a)

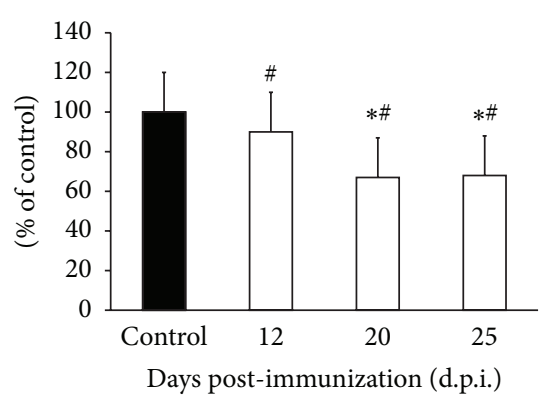

(c)

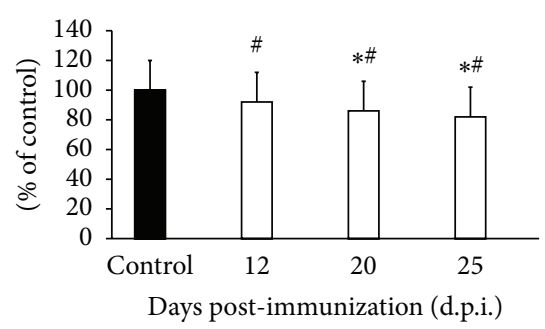

(e)

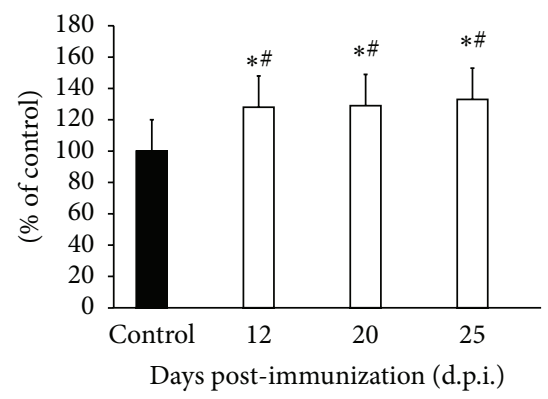

$(\mathrm{g})$

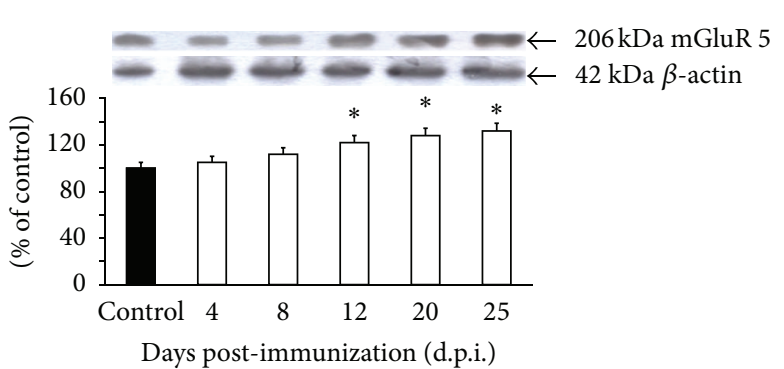

(b)

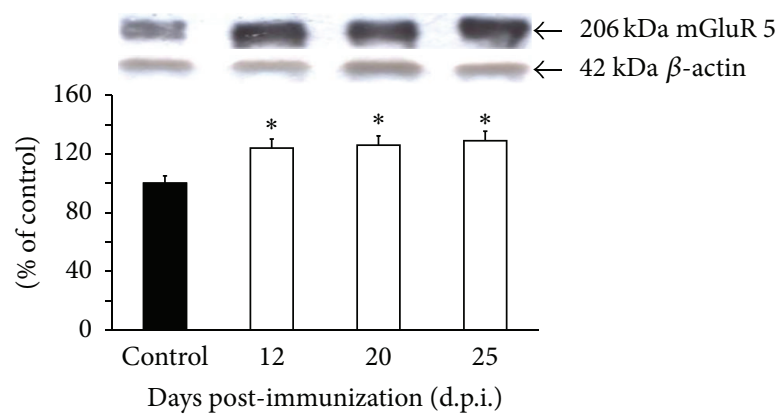

(d)

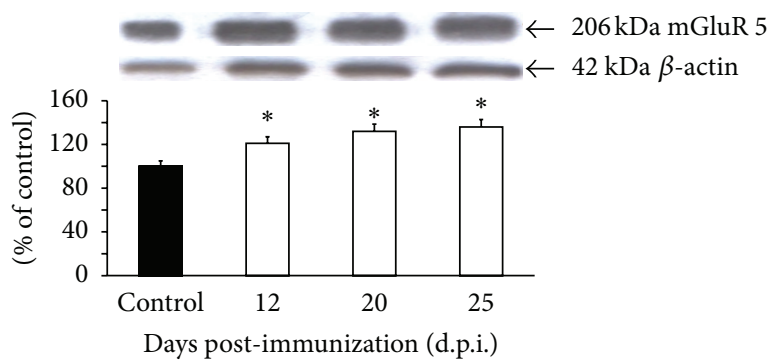

(f)

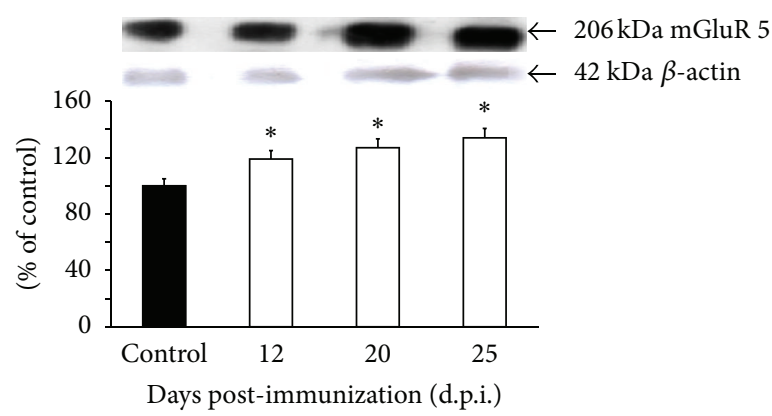

(h)

Figure 4: Expression of mGluR5 mRNA (a, c, e, and g) and protein (b, d, f, and h) in forebrain of control rats and rats with EAE at different times post-immunization ( $a$ and $b$ ) and after therapeutic treatment with antagonists of glutamate receptors: amantadine (c and $d$ ), memantine (e and f), and MPEP ( $g$ and h). Total RNA was prepared from healthy control rats, rats with EAE, and rats with EAE after therapy at the indicated d.p.i. The mGluR5 mRNA levels were determined by quantitative real-time PCR (see Section 2) and normalized to actin. Graphs (a), (c), (e), and (g) present the results expressed as percentage of control from four independent experiments. ${ }^{*} P<0.05$; ${ }^{* *} P<0.01$; ${ }^{* * *} P<0.001$ significantly different versus control (healthy untreated rats). ${ }^{\#} P<0.05$; ${ }^{\# \#} P<0.01$; ${ }^{\# \# \#} P<0.001$ significantly different versus rats with EAE not subjected to therapy at the corresponding d.p.i. (one-way ANOVA followed by Dunnett's multiple comparison posttest). Representative immunoblots show the expression of mGluR5 receptor protein in forebrain homogenates of (b) control rats and rats with EAE at different times post-immunization, (d) amantadine-treated rats with EAE, (f) memantine-treated rats with EAE, and (h) MPEPtreated rats with EAE. The results are expressed as percentage of control. Graphs (b), (d), (f), and (h) present the results of densitometric analysis, normalized to $\beta$-actin, of four independent immunoblots, each done from distinct brain; ${ }^{*} P<0.05$ (one-way ANOVA with post hoc Dunnett's test). 


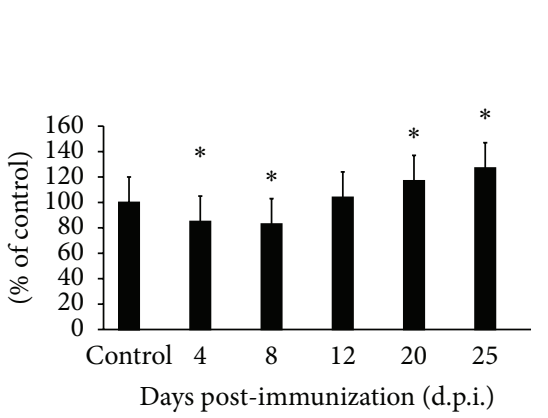

(a)

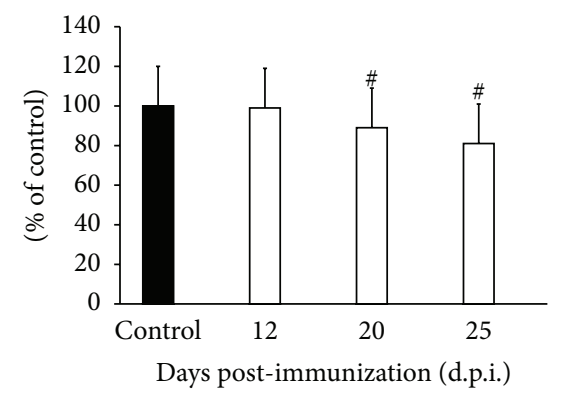

(c)

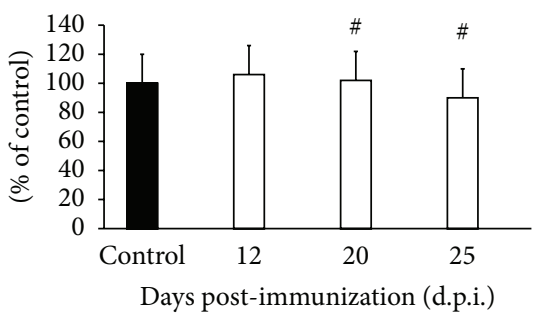

(e)

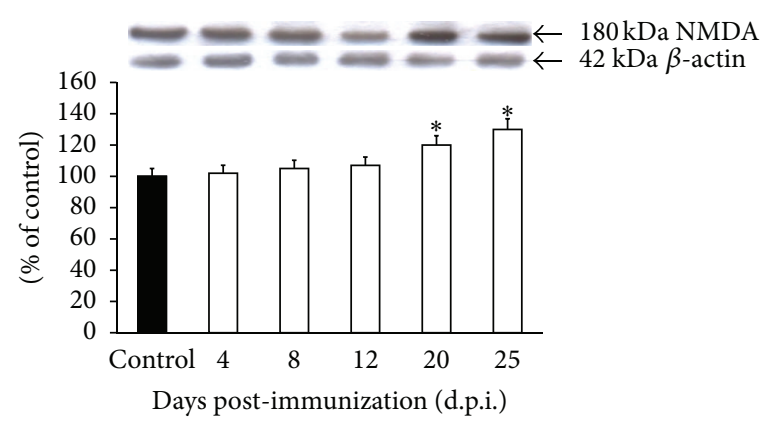

(b)

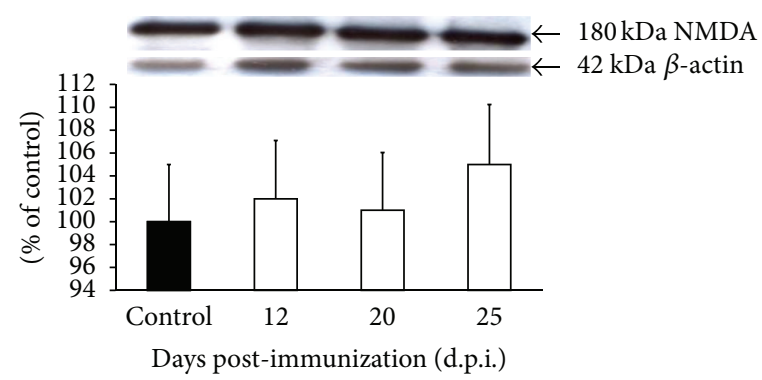

(d)

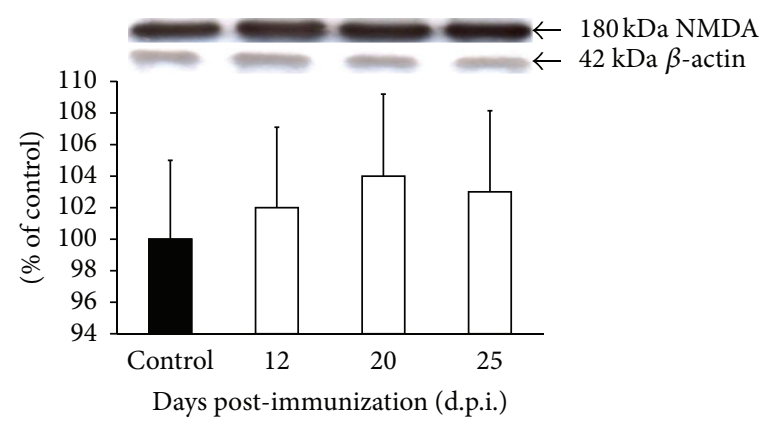

(f)

FIGURE 5: Expression of mRNA of NMDARs (a, c, and e) and protein (b, $d$, and $f$ ) in forebrain of control and EAE rats at different times postimmunization ( $\mathrm{a}$ and $\mathrm{b}$ ) and after therapeutic treatment with antagonists of NMDA receptors: amantadine ( $\mathrm{c}$ and $\mathrm{d}$ ) and memantine (e and f). Total RNA was prepared from healthy control rats, rats with EAE, and rats with EAE after therapy at the indicated d.p.i. Levels of NMDA mRNAs were determined by quantitative real-time PCR (see Section 2) and normalized to actin. Graphs (a), (c), and (e) present the results expressed as percentage of control from four independent experiments. ${ }^{*} P<0.05$ versus control (one-way ANOVA followed by Dunnett's multiple comparison posttest). Representative immunoblots show the expression of NMDA receptor protein in forebrain homogenates of (b) control rats and rats with EAE at different times post-immunization, (d) amantadine-treated rats with EAE, and (f) memantine-treated rats with EAE. The results are expressed as percentage of control. Graphs (b), (d), and (f) present the results of densitometric analysis of four independent immunoblots, normalized to $\beta$-actin, each done from distinct brain. ${ }^{*} P<0.05$ (one-way ANOVA with post hoc Dunnett's test).

immunization (Figures 4(c) and 4(e)). In contrast, expression of mGluR5 protein was practically unchanged (Figures 4(d) and 4(f)). Administration of the mGluR5 antagonist MPEP caused an increase in the level of mGluR 5 mRNA by approximately $40 \%$ over the control values (Figure $4(\mathrm{~g})$ ). At the protein level, mGluR5 expression was about $20 \%$ higher (Figure 4(h)).

Observations of NMDAR expression at the mRNA level revealed a reduction of about $20-30 \%$ at the early time points after immunization ( $4-8$ d.p.i.) and a $10-15 \%$ increase (Figure 5(a)) in the later phase of the disease (12-25 d.p.i.). Enhancement of NMDA receptor protein expression by approximately $10 \%$ was observed only in the late phase (20-25 d.p.i.) (Figure 5(b)). Administration of tested NMDA receptor antagonists (amantadine and memantine) resulted in a slight decrease of NMDA mRNA (Figures 5(c) and 5(e)), while the changes in protein levels, although noticeable, were found to be statistically insignificant (Figures 5(d) and $5(\mathrm{f}))$.

Coadministration of NMDAR antagonists (amantadine and memantine) with antagonists of group I mGluR (LY36785 and MPEP) did not have a further influence on the levels of protein or mRNA expression of the tested receptors (data not shown). 


\section{Discussion}

Glutamate is the primary excitatory amino acid in the mammalian CNS. When released from presynaptic terminals, glutamate activates the ionotropic NMDA, AMPA, and KA and metabotropic receptors (mGluRs). This can lead to the excitatory signaling which underlies processes operating during development, plasticity, learning, and memory $[1,11,13$, 24]. Glutamate is not metabolized by extracellular enzymes. Ninety percent of extracellular glutamate concentration released from nerve endings is removed by reuptake to the astrocytes and neurons. Excitatory amino acid transporters (EAATs) are involved in this process. Regulation within the synaptic cleft is critical to limit the overstimulation of excitatory amino acid receptors. Multiple neurodegenerative diseases, including MS, have been associated with changes in expression and function of glutamate receptors and glutamate transporters $[1,3,4,8]$.

Our earlier study showed changes in protein expression of glutamate transporters (GLT-1 and GLAST) in cerebellum and forebrain of rats subjected to EAE. We observed a statistically significant reduction in protein levels of both glutamate transporters in the acute phase of EAE and during the recovery ( 25 d.p.i.) that may result in lowering of glutamate clearance and lead to insufficient protection against glutamate excitotoxicity [25]. When the level of glutamate increases in the synaptic cleft, disturbances can occur in the signaling process and in the activity of glutamate receptors. Excitotoxic damage of nerve tissue is a common pathological event which accompanies overstimulation of glutamate receptors and changes in glutamate transport [26,27].

In the present study, we investigated whether drugs such as LY 367385 (a mGluR1 selective antagonist) MPEP (a mGluR5 antagonist) and amantadine and memantine (antagonists of NMDA glutamate receptors, which inhibit excitatory glutamatergic neurotransmission through different mechanisms), have neuroprotective effects in the established rat model of MS. We also expected that combined treatment with NMDARs and mGluRs antagonists would furthermore improve the condition of rats with EAE. The method of administration and optimal therapeutic doses of amantadine, memantine, LY 367385, and MPEP were selected on the basis of previously published data $[5,15,17,28-30]$.

It has been generally accepted that acute excitotoxic degeneration of neurons evoked by glutamate is mediated mainly by NMDA receptors, whose activation leads to a massive accumulation of $\mathrm{Ca}^{2+}$ of extracellular origin inside the cells $[4,31]$ and further to increases in the intracellular concentrations of $\mathrm{Ca}^{2+}$ to pathological levels. The potential use of antagonists of NMDARs as neuroprotective agents has been established in preclinical studies [16, 32-34]. Memantine has been found to reduce the lethality of neurons when used against NMDA- or homocysteine-induced excitotoxicity in organotypic hippocampal slices and in cultured neurons $[35,36]$, or against excitotoxic brain damage in animal models of diseases [15, 18]. Amantadine and memantine have also been found to be effective in relieving symptoms of multiple sclerosis or EAE pathology [28, 34, 37, 38].
Similarly, in our experiments, the antagonists of NMDA receptors were found to effectively reduce the development and duration of neurological deficits during therapy of EAE rats, and were found to be effective in modifying all of the assessed parameters of the disease. We observed reduction in neurological scores by amantadine and memantine administered prophylactically from day 7 to 11 after immunization, that is, when the symptoms of EAE were not evident. The clinical status of treated animals was significantly improved, and the severity of neurological deficits was reduced. After therapy, the disease score decreased to 2.5 , while in untreated animals it remained at 4.5. In addition, the duration of disease was reduced by about 2-3 days, whereas the inductive phase was prolonged by about 2 days relative to untreated rats.

On the other hand, electrophysiological experiments have identified a modulatory effect of postsynaptically located group I mGluRs on NMDAR activity resulting in enhancement of NMDAR-evoked responses in many parts of the brain $[11,13,39,40]$. In turn, presynaptically-located mGluRs of group I have been shown to act as release-enhancing autoreceptors mediating the acceleration of glutamate exocytosis on glutamatergic synapses [41-44].

Therefore, antagonists of group I mGluRs are substances which can inhibit the stimulating functions of the CNS. This appears promising for therapy of neurodegenerative disorders $[45,46]$. These antagonists were also found to exhibit neuroprotection in mixed cortical neuron cultures, brain injury during ischemia and in animal models of neurodegenerative diseases $[5,15,29,30]$.

Based on these data, we expected to observe enhancement of neuroprotection in rats with EAE which were subjected to combined therapy with antagonists of both types of glutamate receptors (NMDARs and mGluRs). However, our results suggest that inhibition of the NMDARs by amantadine and memantine is sufficient to ameliorate the symptoms of EAE. Antagonists of group I mGluRs (LY 367385 and MPEP) did not influence the condition of the treated animals when they were administered alone. Moreover, even when administered in combination with amantadine and memantine, these antagonists did not improve neurological deficits.

The results of our experiments indicate an increase of protein and mRNA levels of group I mGluRs (mGluR1 and mGluR5) during the course of EAE in untreated rats when compared with controls. The increased expression of mGluR1 and mGluR5 protein and mRNA levels, which started within 8-12 d.p.i. and lasted until to the end of experiment, was found be to correlated with the acute symptomatic phase of the disease. Somewhat lesser and later occurring changes in the expression of ionotropic NMDARs were observed (20-25 d.p.i.). This suggests that both types of glutamatergic receptors are involved in the pathomechanisms of EAE and may participate in excitotoxic brain damage during the course of the disease. Overexpression of glutaminergic receptors might be observed when the concentration of extracellular glutamate in the brain is increased, particularly for a prolonged period $[1,2,7,30]$. Thus, the increased expression we identified may reflect a response to the excess of glutamate and overactivation of the glutamatergic system. 
Therapy with both antagonists of NMDARs (amantadine and memantine) and mGluRs (LY 367385 and MPEP) did not have a significant influence on the protein levels of the receptors. However, we observed a statistically significant difference in mRNA expression of the receptors in the treated animals. Administration of both amantadine and memantine was found to decrease expression of mGluR1 and mGluR5 mRNA gradually to the lowest level at 25 d.p.i. The duration of the experiment was probably sufficient to evoke the response in expression of mRNA but not in expression of protein.

Blocking of NMDA receptors with amantadine and memantine induces feedback action to decrease the levels of glutamate released from synaptic vesicles into extracellular space, which, in the longer timeframe of 20-25 d.p.i., results in reduced expression of mRNA for both mGluR1 and mGluR5. The opposite effect was found to be induced by mGluR antagonists (LY 367385 and MPEP). This suggests that, despite blocking of mGluRs by their antagonists, the excessive release of glutamate to the extracellular space is not inhibited and receptors remain over-stimulated. Indeed, it has been shown that blocking of NMDARs decreases the feedback of synaptically released glutamate $[9,12,26,47]$. This shows that NMDA receptors play an important role during the course of EAE.

Thus, it appears that exclusively blocking the activity of NMDARs, rather than total blockade of different types of glutamate receptors, is sufficient to obtain effective reduction of the consequences of elevated glutamate levels in rats with EAE. This finding is in agreement with the results of a previous study of mice with EAE in which prophylactic administration of riluzole, an inhibitor of glutamate-dependent neurotransmission, was found to reduce neurological severity, inflammation, demyelination, and overstimulation of GluRs [48].

\section{Conclusions}

The results of our study demonstrate that some glutamate receptors are implicated in neurodegenerative processes which occur during EAE pathology. Data from the literature indicate various mechanisms of functional coupling between group I mGluRs and NMDARs. This indicates that excitoxicity and neurodegenerative processes occurring during the course of EAE may be mediated by the cooperative action of group I mGluRs and NMDARs. Indeed, the antagonists of NMDARs (amantadine and memantine) exert the neuroprotective effect and significantly inhibit the neurological deficits in rats with EAE. However, a neuroprotective effect was not observed when group I mGluRs antagonists (LY 367385 and MPEP) were administered separately or in combination with amantadine or memantine. Neither the general condition of the experimental animals nor the neurological deficits were improved. However, all of the antagonists investigated in this work have the effect of modifying the expression of mRNA but not protein expression of group I mGluRs and NMDARs relative to the untreated rats with EAE.

\section{Abbreviations}

AMPA: $\quad \alpha$-Amino-3-hydroxy-5-methyl-4isoxazolepropionate

ANOVA: Analysis of variance

d.p.i.: Days post-immunization

EAATs: Excitatory amino acid transporters

EAE: Experimental autoimmune encephalomyelitis

GLAST: Glutamate-aspartate transporter

GLT-1: Glutamate transporter 1

GluRs: Glutamate receptors

iGluRs: Ionotropic glutamate receptors

KA: $\quad$ Kainate type glutamate receptors

LY 367385: (S-2-Methyl-4-carboxyphenylglycine)competitive antagonist of mGluR1

mGluRs: Metabotropic glutamate receptors

MPEP: (2-Methyl-6-(phenylethynyl)-pyridine)-

MS: $\quad$ Multiple sclerosis

NMDA: N-Methyl-D-aspartate

NMDARs: NMDA receptors.

\section{Acknowledgments}

The authors wish to thank Professor Małgorzata Chalimoniuk (Department of Cellular Signaling, Mossakowski Medical Research Centre, Polish Academy of Sciences, Warsaw, Poland) for collaboration, suggestions, and assistance during the real-time PCR experiments. This study was supported by Grant no. NN401 620038 from the Polish Ministry of Science and Higher Education.

\section{References}

[1] A. J. Groom, T. Smith, and L. Turski, "Multiple sclerosis and glutamate," Annals of the New York Academy of Sciences, vol. 993, pp. 229-275, 2003.

[2] D. Pitt, P. Werner, and C. S. Raine, "Glutamate excitotoxicity in a model of multiple sclerosis," Nature Medicine, vol. 6, no. 1, pp. 67-70, 2000.

[3] J. J. G. Geurts, G. Wolswijk, L. Bö et al., "Altered expression patterns of group I and II metabotropic glutamate receptors in multiple sclerosis," Brain, vol. 126, no. 8, pp. 1755-1766, 2003.

[4] D. W. Choi, "Calcium and excitotoxic neuronal injury," Annals of the New York Academy of Sciences, vol. 747, pp. 162-171, 1994.

[5] J. M. H. Anneser, G. Domenico Borasio, A. Berthele, W. Zieglgänsberger, and T. R. Tölle, "Differential expression of group I metabotropic glutamate receptors in rat spinal cord somatic and autonomic motoneurons: possible implications for the pathogenesis of amyotrophic lateral sclerosis," Neurobiology of Disease, vol. 6, no. 2, pp. 140-147, 1999.

[6] S. R. Bradley, M. J. Marino, M. Wittmann et al., "Activation of group II metabotropic glutamate receptors inhibits synaptic excitation of the substantia nigra pars reticulata," The Journal of Neuroscience, vol. 20, no. 9, pp. 3085-3094, 2000.

[7] V. Brunos, A. Copani, T. Knöpfel et al., "Activation of metabotropic glutamate receptors coupled to inositol phospholipid hydrolysis amplifies NMDA-induced neuronal degeneration in cultured cortical cells," Neuropharmacology, vol. 34, no. 8, pp. 1089-1098, 1995. 
[8] S. D’Antoni, A. Berretta, G. Seminara et al., "A prolonged pharmacological blockade of type-5 metabotropic glutamate receptors protects cultured spinal cord motor neurons against excitotoxic death," Neurobiology of Disease, vol. 42, no. 3, pp. 252-264, 2011.

[9] A. Pisani, P. Gubellini, P. Bonsi et al., "Metabotropic glutamate receptor 5 mediates the potentiation of $\mathrm{N}$-methyl-D-aspartate responses in medium spiny striatal neurons," Neuroscience, vol. 106, no. 3, pp. 579-587, 2001.

[10] Y. Ganor, M. Besser, N. Ben-Zakay, T. Unger, and M. Levite, "Human $\mathrm{T}$ cells express a functional ionotropic glutamate receptor GluR3, and glutamate by itself triggers integrin-mediated adhesion to laminin and fibronectin and chemotactic migration," Journal of Immunology, vol. 170, no. 8, pp. 43624372, 2003.

[11] R. Anwyl, "Metabotropic glutamate receptors: electrophysiological properties and role in plasticity," Brain Research Reviews, vol. 29, no. 1, pp. 83-120, 1999.

[12] L. Mao and J. Q. Wang, "Group I metabotropic glutamate receptor-mediated calcium signalling and immediate early gene expression in cultured rat striatal neurons," The European Journal of Neuroscience, vol. 17, no. 4, pp. 741-750, 2003.

[13] A.-M. White, R. A. Kylänpää, L. A. Christie, S. J. McIntosh, A. J. Irving, and B. Platt, "Presynaptic group I metabotropic glutamate receptors modulate synaptic transmission in the rat superior colliculus via 4-AP sensitive $\mathrm{K}+$ channels," British Journal of Pharmacology, vol. 140, no. 8, pp. 1421-1433, 2003.

[14] J. Perroy, F. Raynaud, V. Homburger et al., "Direct interaction enables cross-talk between ionotropic and group I metabotropic glutamate receptors," Journal of Biological Chemistry, vol. 283, no. 11, pp. 6799-6805, 2008.

[15] C. Paul and C. Bolton, "Modulation of blood-brain barrier dysfunction and neurological deficits during acute experimental allergic encephalomyelitis by the $\mathrm{N}$-methyl-D-aspartate receptor antagonist memantine," Journal of Pharmacology and Experimental Therapeutics, vol. 302, no. 1, pp. 50-57, 2002.

[16] S. L. Erdo and M. Schaffer, "Memantine is highly potent in protecting cortical cultures against excitotoxic cell death evoked by glutamate and N-methyl-D-aspartate," European Journal of Pharmacology, vol. 198, no. 2-3, pp. 215-217, 1991.

[17] E. Ziemińska, A. Stafiej, and J. W. Łazarewicz, "Role of group I metabotropic glutamate receptors and NMDA receptors in homocysteine-evoked acute neurodegeneration of cultured cerebellar granule neurones," Neurochemistry International, vol. 43, no. 4-5, pp. 481-492, 2003.

[18] D. Makarewicz, M. Duszczyk, R. Gadamski, W. Danysz, and J. W. Łazarewicz, "Neuroprotective potential of group I metabotropic glutamate receptor antagonists in two ischemic models," Neurochemistry International, vol. 48, no. 6-7, pp. 485-490, 2006.

[19] M. Kerschensteiner, C. Stadelmann, B. S. Buddeberg et al., "Animal model-targeting experimental autoimmune encephalomyelitis lesions to a predetermined axonal tract system allows for refined behavioral testing in an animal model of multiple sclerosis," American Journal of Pathology, vol. 164, no. 4, pp. 1455-1469, 2004.

[20] R. Meyer, R. Weissert, R. Diem et al., "Acute neuronal apoptosis in a rat model of multiple sclerosis," The Journal of Neuroscience, vol. 21, no. 16, pp. 6214-6220, 2001.

[21] M. Ohgoh, T. Hanada, T. Smith et al., "Altered expression of glutamate transporters in experimental autoimmune encephalomyelitis," Journal of Neuroimmunology, vol. 125, no. 1-2, pp. 170-178, 2002.

[22] O. H. Lowry, N. J. Rosenbrough, A. L. Farr, and R. J. Randal, "Protein measurement with the Folin phenol reagent," The Journal of Biological Chemistry, vol. 193, no. 1, pp. 265-275, 1951.

[23] U. K. Laemmli, "Cleavage of structural proteins during the assembly of the head of bacteriophage T4," Nature, vol. 227, no. 5259, pp. 680-685, 1970.

[24] G. D. Zeevalk and W. J. Nicklas, "Evidence that the loss of the voltage-dependent $\mathrm{Mg} 2+$ block at the $\mathrm{N}$ - methyl-D-aspartate receptor underlies receptor activation during inhibition of neuronal metabolism," Journal of Neurochemistry, vol. 59, no. 4, pp. 1211-1220, 1992.

[25] K. Mitosek-Szewczyk, G. Sulkowski, Z. Stelmasiak, and L. Struzyńska, "Expression of glutamate transporters GLT-1 and GLAST in different regions of rat brain during the course of experimental autoimmune encephalomyelitis," Neuroscience, vol. 155, no. 1, pp. 45-52, 2008.

[26] P. K. Stys and S. A. Lipton, "White matter NMDA receptors: an unexpected new therapeutic target?" Trends in Pharmacological Sciences, vol. 28, no. 11, pp. 561-566, 2007.

[27] G. Sulkowski, B. Dąbrowska-Bouta, B. Kwiatkowska-Patzer, and L. Struzyńska, "Alterations in glutamate transport and group I metabotropic glutamate receptors in the rat brain during acute phase of experimental autoimmune encephalomyelitis," Folia Neuropathologica, vol. 47, no. 4, pp. 329-337, 2009.

[28] I. N. Abdurasulova, S. E. Serdyuk, and V. E. Gmiro, "Combined blockade of GLUR1 AMPA and NMDA receptors effectively eliminates neurological disorders in rats with experimental allergic encephalomyelitis," Eksperimental'naya i Klinicheskaya Farmakologiya, vol. 70, no. 4, pp. 15-19, 2007.

[29] G. Battaglia, V. Bruno, A. Pisani et al., "Selective blockade of type-1 metabotropic glutamate receptors induces neuroprotection by enhancing gabaergic transmission," Molecular and Cellular Neuroscience, vol. 17, no. 6, pp. 1071-1083, 2001.

[30] P. Popoli, A. Pintor, M. T. Tebano et al., "Neuroprotective effects of the mGlu5R antagonist MPEP towards quinolinic acidinduced striatal toxicity: involvement of pre- and post-synaptic mechanisms and lack of direct NMDA blocking activity," Journal of Neurochemistry, vol. 89, no. 6, pp. 1479-1489, 2004.

[31] M. J. Berridge, M. D. Bootman, and P. Lipp, "Calcium-a life and death signal," Nature, vol. 395, no. 6703, pp. 645-648, 1998.

[32] H.-S. V. Chen, J. W. Pellegrini, S. K. Aggarwal et al., "Openchannel block of N-methyl-D-aspartate (NMDA) responses by memantine: therapeutic advantage against NMDA receptormediated neurotoxicity," The Journal of Neuroscience, vol. 12, no. 11, pp. 4427-4436, 1992.

[33] H.-S. V. Chen and S. A. Lipton, "The chemical biology of clinically tolerated NMDA receptor antagonists," Journal of Neurochemistry, vol. 97, no. 6, pp. 1611-1626, 2006.

[34] R. Sandyk, G. Awerbuch, and G. Subramanian, "Failure of amantadine hydrochloride to alter immune responses in the experimental allergic encephalomyelitis model of neuroautoimmune disease," The International Journal of Neuroscience, vol. 40, no. 3-4, pp. 303-306, 1988.

[35] C. Volbracht, J. van Beek, C. Zhu, K. Blomgren, and M. Leist, "Neuroprotective properties of memantine in different in vitro and in vivo models of excitotoxicity," The European Journal of Neuroscience, vol. 23, no. 10, pp. 2611-2622, 2006.

[36] E. Zieminska and J. W. Lazarewicz, "Excitotoxic neuronal injury in chronic homocysteine neurotoxicity studied in vitro: the role 
of NMDA and group I metabotropic glutamate receptors," Acta Neurobiologiae Experimentalis, vol. 66, no. 4, pp. 301-309, 2006.

[37] B. Elahi, N. Phielipp, and R. Chen, "N-methyl-D-aspartate antagonists in levodopa induced dyskinesia: a meta-analysis," The Canadian Journal of Neurological Sciences., vol. 39, no. 4, pp. 465-472, 2012.

[38] T. N. Fedorova, G. K. H. Bagyeva, I. S. Dobrotvorskaia et al., "Mexidant increases the effectiveness of levadopa treatment of Parkinson's disease," Eksprimental'naia i Klinicheskaia. Farmakologiia, vol. 75, no. 6, pp. 23-26, 2012 (Russian).

[39] A. Losonczy, P. Somogyi, and Z. Nusser, "Reduction of excitatory postsynaptic responses by persistently active metabotropic glutamate receptors in the hippocampus," Journal of Neurophysiology, vol. 89, no. 4, pp. 1910-1919, 2003.

[40] A. M. Watabe, H. J. Carlisle, and T. J. O’Dell, "Postsynaptic induction and presynaptic expression of group 1 mGluRdependent LTD in the hippocampal CA1 region," Journal of Neurophysiology, vol. 87, no. 3, pp. 1395-1403, 2002.

[41] A. Fazal, F. Parker, A. M. Palmer, and M. J. Croucher, "Characterisation of the actions of group I metabotropic glutamate receptor subtype selective ligands on excitatory amino acid release and sodium-dependent re-uptake in rat cerebrocortical minislices," Journal of Neurochemistry, vol. 86, no. 6, pp. 13461358, 2003.

[42] D. Manahan-Vaughan, "Group 1 and 2 metabotropic glutamate receptors play differential roles in hippocampal long-term depression and long-term potentiation in freely moving rats," The Journal of Neuroscience, vol. 17, no. 9, pp. 3303-3311, 1997.

[43] A. Rodríguez-Moreno, A. Sistiaga, J. Lerma, and J. SánchezPrieto, "Switch from facilitation to inhibition of excitatory synaptic transmission by group I mGluR desensitization," Neuron, vol. 21, no. 6, pp. 1477-1486, 1998.

[44] J. Cartmell and D. D. Schoepp, "Regulation of neurotransmitter release by metabotropic glutamate receptors," Journal of Neurochemistry, vol. 75, no. 3, pp. 889-907, 2000.

[45] I. Brabet, S. Mary, J. Bockaert, and J.-P. Pin, "Phenylglycine derivatives discriminate between mGluR1- and mGluR5-mediated responses," Neuropharmacology, vol. 34, no. 8, pp. 895-903, 1995.

[46] J. W. Lazarewicz, A. Ziembowicz, E. Matyja, A. Stafiej, and E. Zieminska, "Homocysteine-evoked 45Ca release in the rabbit hippocampus is mediated by both NMDA and group I metabotropic glutamate receptors: in vivo microdialysis study," Neurochemical Research, vol. 28, no. 2, pp. 259-269, 2003.

[47] S. A. Lipton, "Paradigm shift in neuroprotection by NMDA receptor blockade: memantine and beyond," Nature Reviews Drug Discovery, vol. 5, no. 2, pp. 160-170, 2006.

[48] Y. Gilgun-Sherki, H. Panet, E. Melamed, and D. Offen, "Riluzole suppresses experimental autoimmune encephalomyelitis: implications for the treatment of multiple sclerosis," Brain Research, vol. 989, no. 2, pp. 196-204, 2003. 

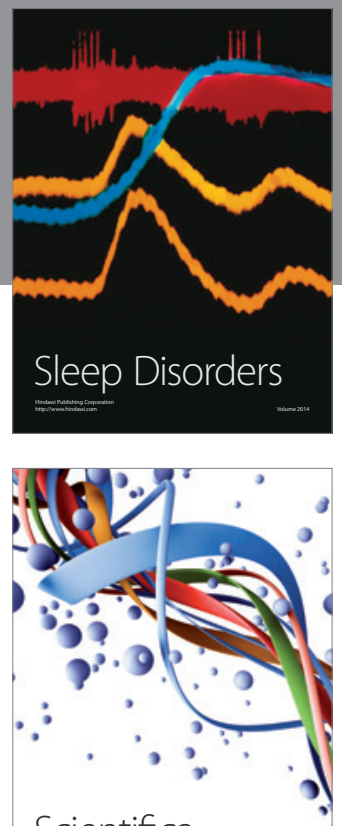

Scientifica
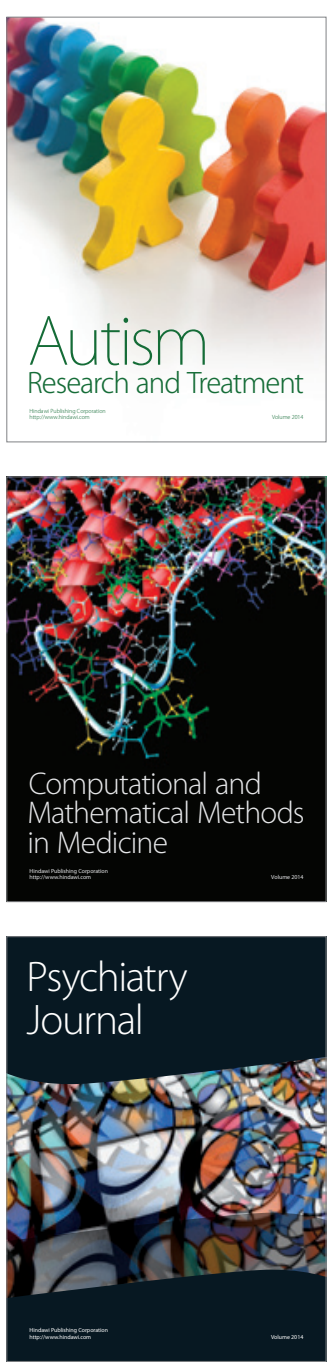
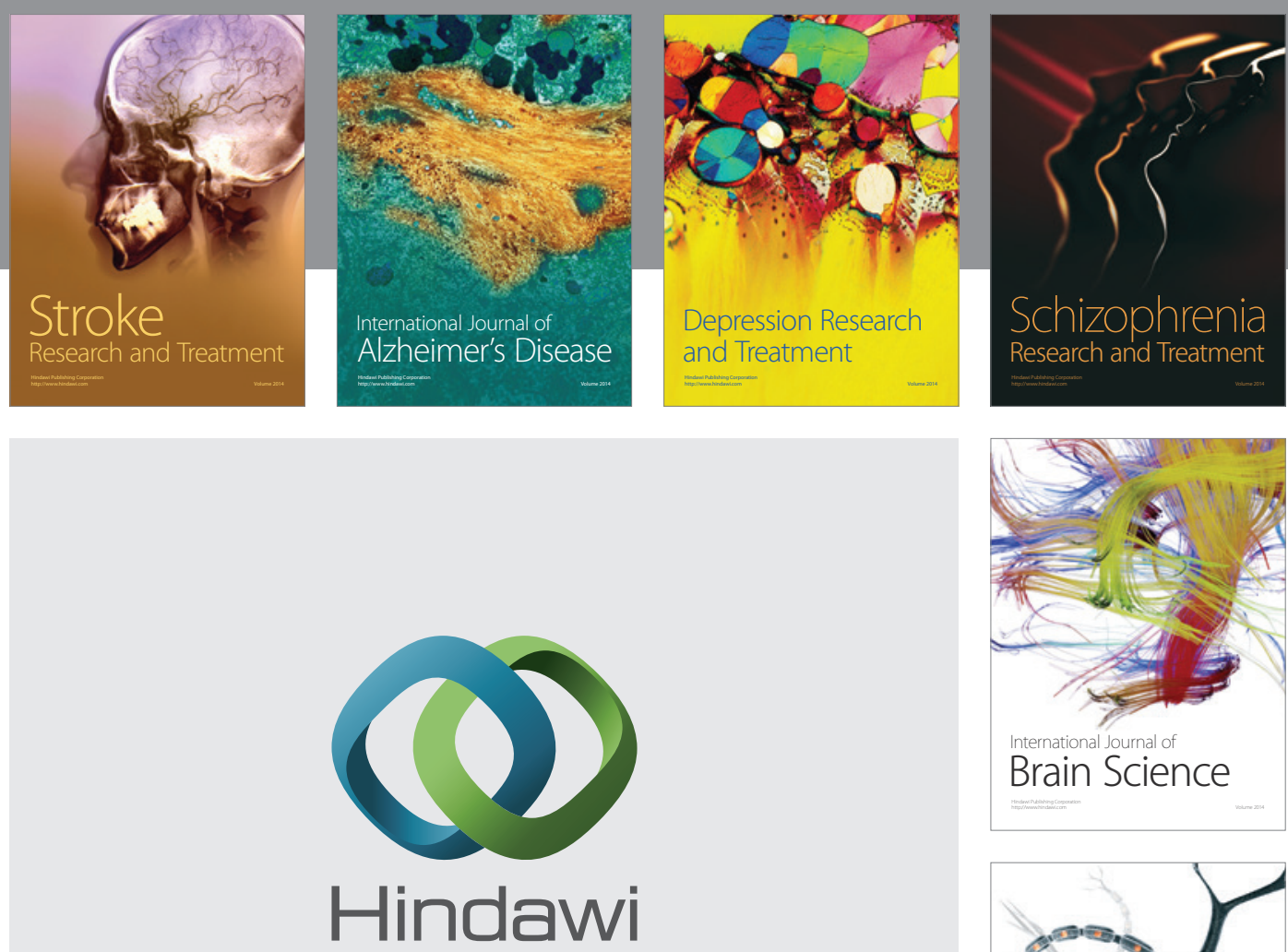

Submit your manuscripts at

http://www.hindawi.com
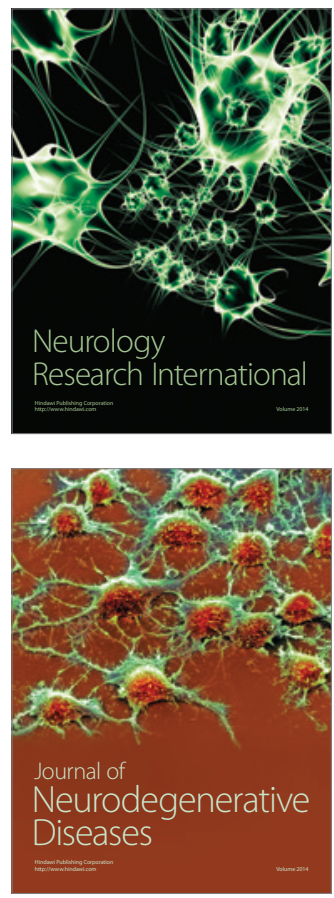

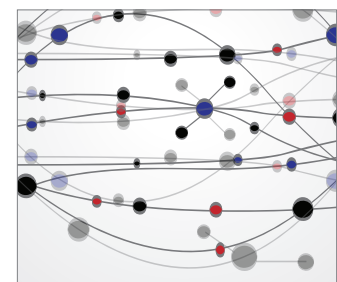

The Scientific World Journal
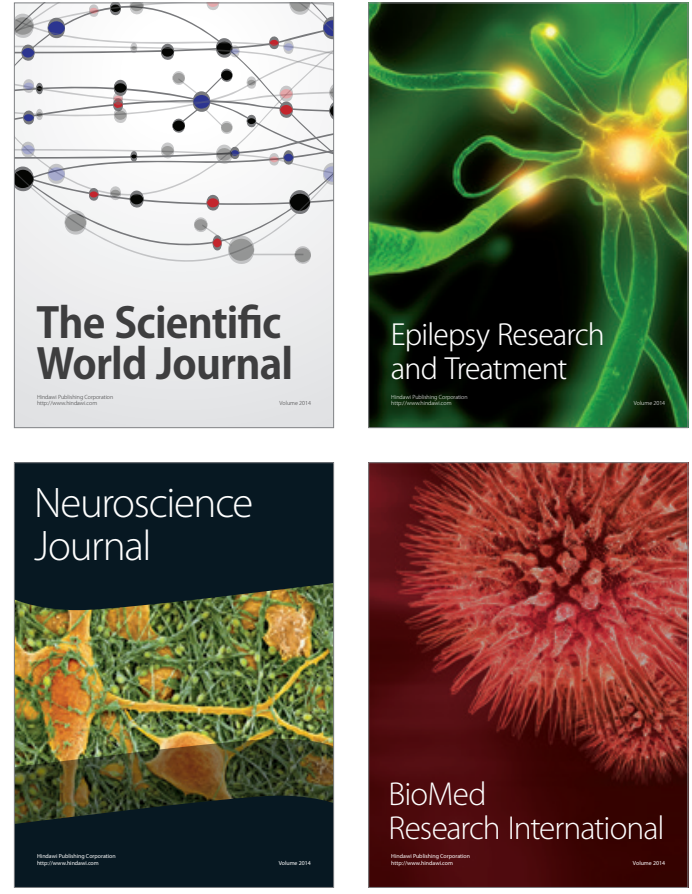

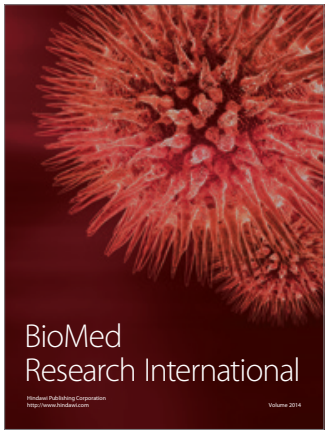

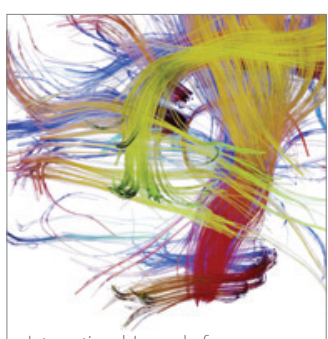

Brain Science

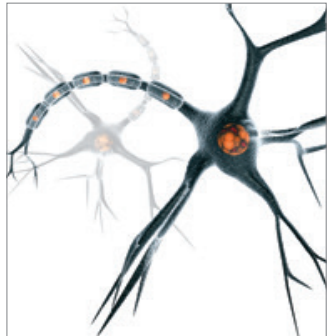

Neural Plasticity
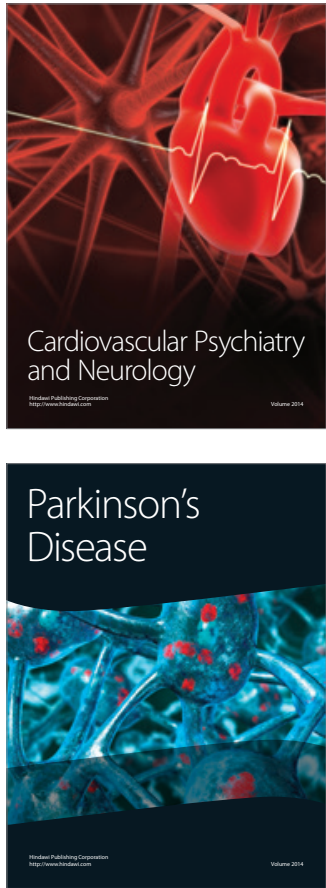